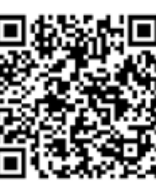

\title{
Olgu Sunumu: Mikro Cerrahiye Yardımcı Bir Metot, Hirudoterapi
}

\author{
A Case Report: Hirudotherapy as a Treatment Modality in the Microsurgery
}

\author{
Suat Arusan, Batu Bayar ${ }^{1}$, Ahmet Gödekmerdan², Naim Sağlam³ \\ 'Doğal Hayat Polikliniği, Ankara, Türkiye \\ ${ }^{2}$ Fırat Üniversitesi Tıp Fakültesi, İmmünoloji Anabilim Dalı, Elazığ, Türkiye \\ ${ }^{3}$ Fırat Üniversitesi Su Ürünleri Fakültesi, Elazığ, Türkiye
}

\section{ÖZET}

Tıbbi sülüklerin kan emme esnasında dokuya 100'den fazla biyoaktif madde salgıladıkları bilinmektedir. Özellikle plastik cerrahide olmak üzere hastalıkların ve belirtilerinin tedavisinde sülükler kullanılmaktadır. Bu yazıda bir kaza sonrası sağ el orta parmak distal falanksı kopmuş 7 yaşındaki bir olgu sunulmuştur. Kopan parça plastik cerrahi kliniğinde yerine dikilmiş ve 15 gün süren tıbbi sülük uygulaması (Hirudo medicinalis) ile tedavi edilmiş̧ir. Hirudoterapiye başladıktan sonra yerine dikilen falanksta doku ödemi azalmış, ağrı kaybolmuş ve yeniden damarlanma başlamıştır. Başta kopan parmak ve flepler olmak üzere plastik ve rekonstrüktif cerrahi uygulamalarında öncelikli olmak kaydı ile Türk hekimleri hiroduterapinin, avantajlarının farkında olmalıdılar. (Turkiye Parazitol Derg 2013; 37: 154-6)

Anahtar Sözcükler: Mikro-cerrahi, tıbbi sülük, hirudoterapi

Geliş Tarihi: 11.08.2011 Kabul Tarihi: 08.12.2012

\section{ABSTRACT}

Medicinal leeches are known to inject more than 100 bioactive substances in the tissue whilst sucking blood. They are being successfully used for the treatment of diseases and symptoms, especially in plastic surgery. We report the case of a 7-year old boy, who had lost the first phalanx of the middle finger of the right hand after an accident. The detached digit was replanted in the plastic surgery clinic, and treated within a period of 15 days with medicinal leeches (Hirudo medicinalis). Soon after the initiation of the hirudotherapy, the revascularisation of the re-attached phalanx, as well as the resolving of tissue oedema and pain was observed. Turkish physicians should be aware of the advantages of hirudotherapy in plastic and reconstructive surgery, especially in cases of detached digits and flaps.

(Turkiye Parazitol Derg 2013; 37: 154-6)

Key Words: Micro-surgery, medicinal leech, hirudotherapy

Received: 11.08.2011

Accepted: 08.12.2012

\section{Giriş}

Kan emici bir parazit olarak bilinen sülüklerin çok fazla sayıda türü olup bunlardan sadece bir kaçı (Hirudo medicinalis, Hirudo verbana, Hirudo orientalis, Hirudo troctina vb.) tıbbi amaçlarla tedavide kullanılabilmektedir (1). Tıbbi sülükler, çok eski devirlerden beri bazı hastalıkların tedavisinde ve özellikle de doğu tıbbında flebotomi amaçlı olarak

kullanılmaktadır (2-4). Sülük salyasında birbirinden farklı etkileri bulunan 100'ün üstünde biyoaktif madde (vazodilatatörler, antikoagulan moleküller, bakteriyostatikler, analjezikler, antiinflamatuarlar, lokal anestezikler, prostaglandinler, protienazlar vb.) izole edilmiş olup, bunlardan hirudin en iyi bilinen çok güçlü bir antikoagulan moleküldür (1, 5-7). Sülük, kan emme sırasında bu maddeleri dokuya vermektedir. Halen en gelişmiş ülkeler dahil (ABD, Kanada, Almanya, Fransa, Hollanda, Rusya,

Yazışma Adresi / Address for Correspondence: Dr. Ahmet Gödekmerdan, Yıldırım Beyazıt Üniversitesi Tıp Fakültesi Mikrobiyoloji Anabilim Dalı, Ankara, Türkiye Tel: +90 4242333555 E-posta: agodekmerdan@hotmail.com doi:10.5152/tpd.2013.34 
vb.) dünyanın bir çok yerinde, bazı hastalıkların tedavisinde (mikro cerrahi, glokom, hematom, tromboz, gangrene gidişin önlenmesi ile arteriyoskleroz, diabetik damar komplikasyonları ve varisler gibi çeşitli damar bozukluklarında, vb.) tıbbi tedaviye yardımcı olarak kliniklerde (cerrahi, travmatoloji, stomatoloji, oftalmoloji, vb.) hirudoterapi kullanımı artmaktadır. Özellikle, rekonstrüktif cerrahide post operatif sülük kullanımı ile dolaşımın düzenlenmesi ve flapların mikrorevaskülarizasyonu sağlanır (8-12).

Ülkemiz tıbbi sülüklerin bulunması açısından çok şanslı bir durumdadır. Her yıl dünyanın çeşitli ülkelerine, Tarım ve Köyişleri Bakanlığı'nın belli miktarlarda ihracına izın verdiği tıbbi sülüklerin, ülkemiz tıp uygulamalarında da gerektiği kadar öneme sahip olması için hekimlerin bilgilendirilmesi gerekir $(13,14)$. Yazımızda, distal falanksı kopan ve dikilen bir hastanın, parmaktaki ağrısının giderildiği, revaskülarizasyonu hızlandıran ve dokudaki ödemi çözerek dikilen kısmın tutmasına yardımcı olan hirudoterapiye, yeniden Türk hekimlerinin dikkatlerini çekmek amacıyla yer verdik.

\section{OLGU SUNUMU}

Yedi yaşında bir erkek çocuk parkta oyun oynarken sağ el orta parmak distal falanksının kopması nedeni ile bir hastanenin plastik cerrahi kliniğine başvurulduğu, sadece parmak derisinin kopan kısmı tuttuğu ve büyük oranda parmak ucunda ezilmenin de olduğu, aynı gün parmağın kopan kısmının klinikte dikildiği ifade edildi. Dikilen parmakta iki gün içerisinde, gittikçe artan şiddetli bir ağrı ve morarma şikâyetlerinin olduğu ve doktorlar tarafından yapılan muayene sonrası parmağın kopan kısmının tutmadığı, 1-2 gün bekledikten sonra dikilen kısmın yeniden kesilebileceği bildirilmiş. Hastanın babası tarafından bu tür durumlarda sülük tedavisi ile iyi sonuçlar alındığının bilinmesi ve hekimlere duyurmadan 1-2 seans parmak uç kısmından sülük tedavisi yapılması üzerine, hastanın ağrısının geçtiği ve şiddetli olan morarmanın açılmaya başladığı ifade edildi. Babasının isteği ile taburcu edilen hasta, hirudoterapi için kliniğimize başvurdu. Hasta geldiğinde sağ el orta parmak distal falanksta tırnak köküne kadar uzanan krutlu siyanoze, ödemli tırnak ve deri bütünlüğünün bozulduğu crash injuri izlenmekteydi (Resim 1). Kliniğimizde aynı gün hastaya parmak ucundan hirudoterapi uygulamasına başlandı. Illk seansta 3 adet tıbbi sülük (H. medicinalis) biri parmak ucuna, ikisi dikiş yerinin proksimaline lateral tarafından uygulandı (Resim 2). Aynı zamanda, sağ ele torbalama yöntemi (bagging) ile yüksek doz $\left(100 \mu \mathrm{g} / \mathrm{m}^{3}\right)$ ozonterapi yapıldı. Hızlı bir şekilde parmak renginde açılma başladı. Hastanın çok muzdarip olduğu ve parmak ağrısının ilk uygulama neticesinde kaybolduğu ifade edildi. Illk 5 seans sonucu parmağın rengi normale döndü, günde bir seans ve her seansta 3 sülük kullanılarak toplam 15 seans hirudoterapi, günde bir seans olmak üzere 10 seans ozonterapi (bagging) sonrasında parmak tamamen iyileşti (Resim 3). Uygulamada kullanılan her sülük tek bir sefer kullanılarak daha sonra alkol içerisinde imha edildi. İmha edilmiş olan sülükler, belediyenin tıbbi atık imha ekiplerine teslim edildi.

\section{TARTIŞMA}

Tıbbi sülük tedavisinin uygulandığı alanlar içerisinde en dikkat çeken durum, travmatik yaralanma ile kopan bir uzvun dikilmesi sonrası post operatif sülük kullanımı ile mikrorevaskülarizasyonun oluşmasının hızlanmasına ve dolaşımın düzenlenmesine olan ciddi

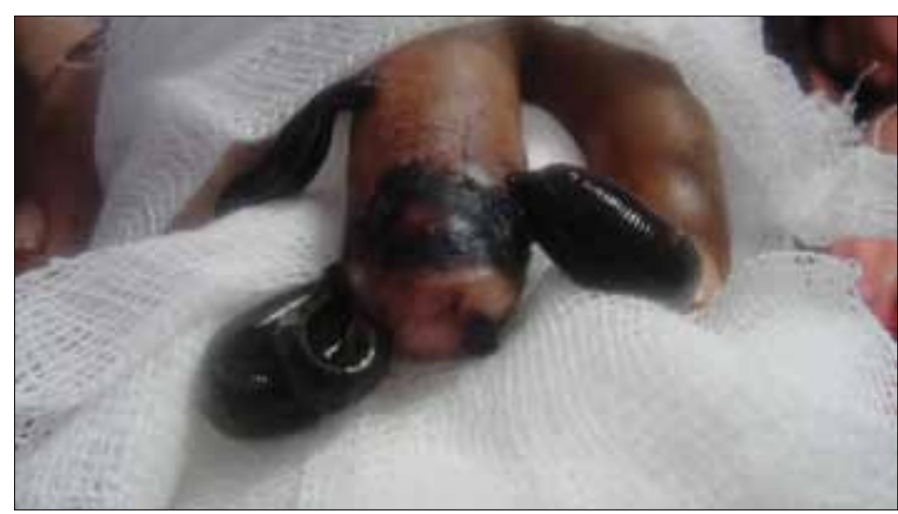

Resim 1. Sülük tedavisi öncesinde parmağın görünümü

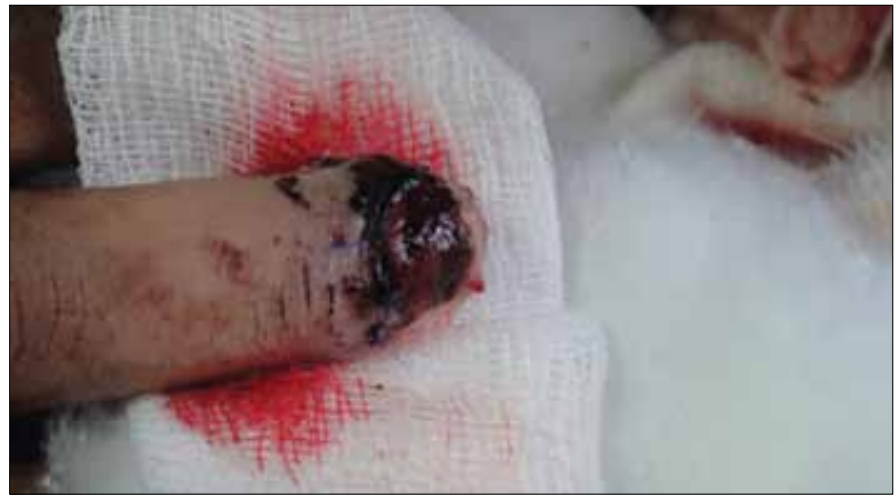

Resim 2. Sülük tedavisi sırasında parmağın görünümü

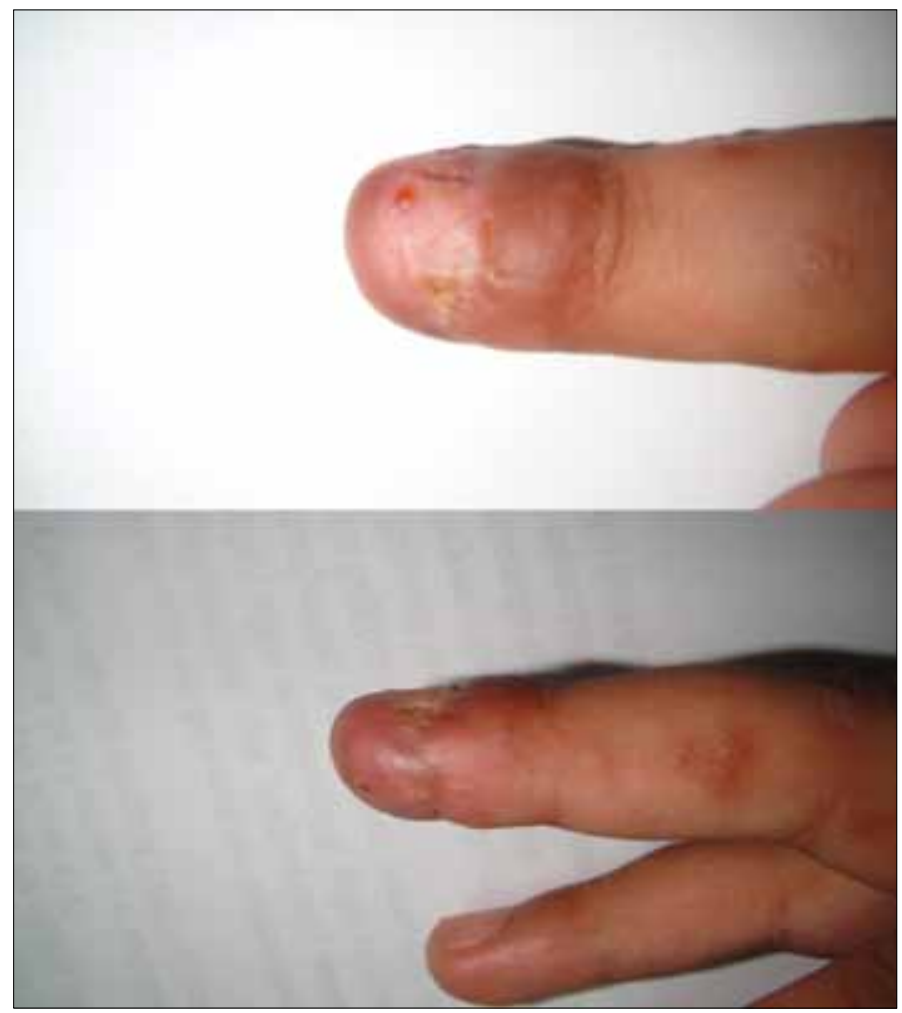

Resim 3. Sülük tedavisi sonrasında parmağın görünümü

katkılarıdır. Bu etkileri, kan emdirme esnasında dokulara verdikleri salyasında bulunan güçlü antikoagulanlar (hirudin ve bdellin) vazodilatatörler, analjezikler, antiinflamatuarlar ve lokal anestezikler 
gibi çeşitli biyoaktif maddelerle sağlarlar. Aynı zamanda, Rusya, Fransa, Hollanda, İsviçre ve İngiltere gibi ülkeler tarafından, bu maddeler sülüklerden saf olarak elde edilip bazı hastalıklarda tedavi amaçı olarak ta kullanılmaktadır. Transplante edilen dokularda, kapiller kan damarlarının birleştirilmesinin zorluğu sebebiyle, bu sistemin gelişip tamamen sirkülasyon sağlanana kadar dokuya oksijenden zengin taze kan gelmesini sağlamak ve dokuda meydana gelen şişliği gidermek amacı ile sülükler kullanılmaktadır. Sülüklerin kan emmesi ile negatif basınç oluşur, dokudaki venöz konjesyon ve artmış venöz basınç düzelir, kapiller akımı artar ve dokuya taze oksijenize kan akımı sağlanır. Hasarlı doku, taze kanla gelen oksijen ve diğer gıdalarla desteklenir $(5,15)$.

Olgumuzda, parmağın kopan distal falanksının dikildikten sonra şiddetli şekilde morarması, şişmesi ve dolaşımın yeterince sağlanamaması sonucu nekroza gidişin başlaması noktasında, dokuya sülük uygulanması ile önlenmiş, önce hastanın şiddetli olan ağrısı geçmiş ve tedavinin etkin olarak sürdürülmesi ile parmak sakatlığı önlenmiştir. Literatürde benzer birçok olgu bildirilmiştir $(8,16,17)$.

Venö-oklüziv deri fleplerınde hirudoterapiyle birlikte hiperbarik oksijen kullanımının doku surveyini iki kat arttırdığı bildirilmiştir $(18,19)$. Bu nedenle, olgumuzda bagging ile yüksek doz $(100 \mu \mathrm{g} /$ $\mathrm{m}^{3}$ ) ozonterapi desteği de sağlandı.

\section{SONUÇ}

Tıbbi literatürde yer alan çok sayıdaki çalışmada ortaya konduğu gibi, hirudoterapinin çeşitli hastalıklardaki tedaviye yardımcı rolü inkar edilemez. Ülkemizin tıbbi sülük kaynağı açısından zengin olduğu ve temin zorluğu olmadığı düşünülürse, özellikle cerrahi alanda çalışanlar başta olmak üzere Türk hekimlerinin bu uygulamadan etkin ve bilinçli bir şekilde yararlanması gerektiğini düşünmekteyiz.

\section{Çıkar Çatışması}

Yazarlar herhangi bir çıkar çatışması bildirmemişlerdir.

Hakem değerlendirmesi: Dış bağımsız.

\section{Yazar Katkıları}

Fikir - A.G; Tasarım - A.G.; Denetleme - A.G.; Kaynaklar - A.G., N.S., S.A.; Malzemeler - S.A., B.B.; Veri toplanması ve/veya işlemesi - A.G., S.A., B.B.; Analiz ve/veya yorum - A.G., N.S., S.A., B.B.; Literatür taraması - A.G., N.S.; Yazıyı yazan - A.G.; Eleştirel Inceleme - N.S., S.A., B.B.; Diğer - A.G., N.S., S.A., B.B.

\section{Conflict of Interest}

No conflict of interest was declared by the authors.

Peer-review: Externally peer-reviewed.

\section{Author Contributions}

Concept - A.G.; Design - A.G.; Supervision - A.G.; Funding - A.G.,
N.S., S.A.; Materials - S.A.; B.B.; Data Collection and/or Processing A.G., S.A., B.B.; Analysis and/or Interpretation - A.G., N.S., S.A., B.B.; Literature Review - A.G., N.S.; Writing - A.G.; Critical Review N.S., S.A., B.B.; Other - A.G., N.S., S.A., B.B.

\section{KAYNAKLAR}

1. Baskova IP, Kostrjukova ES, Vlasova MA, Kharitonova OV, Levitskiy SA, Zavalova LL, et al. Proteins and Peptides of the Salivary Gland Secretion of Medicinal Leeches Hirudo verbana, $\mathrm{H}$. medicinalis, and H. orientalis. Biochemistry (Moscow), 2008; 73: 315-20. [CrossRef]

2. Papavramidou N, Christopoulou-Aletra H. Medicinal use of leeches in the texts of ancient Greek, Roman and early Byzantine writers. Intern Med J 2009; 39: 624-7. [CrossRef]

3. Demirhan A. Folklorik tıpta sülük kullanımı ve evrimsel gelişimi. Tıp Fak Mecm 1979; 42: 523-9.

4. Hoşnuter M, Demircan N, Ünalacak M, Kargı E, Aktunç E, Babucçu O. Modern tıbbın yeniden keşfettiği bir alternatif tedavi metodu: Hirudoterapi. Türk Aile Hek Derg 2003; 7: 177-9.

5. Singh AP. Medicinal leech therapy (hirudotherapy): a brief overview. Complement Ther Clin Pract 2010; 16: 213-5. [CrossRef]

6. Graf J, Kikuchi Y, Rio RV. Leeches and their microbiota: naturally simple symbiosis models. Trends Microbiol 2006; 14: 365-71. [CrossRef]

7. Eldor A, Orevi M, Rigbi M. The role of the leech in medical therapeutics. Blood Reviews 1996; 10: 201-9. [CrossRef]

8. Srivastava A, Sharma R. A brief review on applications of leech therapy Arch Apll Sci Res 2010; 2: 271-4.

9. Sawyer RT. Leech Biology and Behaviour. Clarendan: Oxford; 1986.

10. Whitaker IS, Izadi D, Oliver DW, Monteath G, Butler PE. Hirudo Medicinalis and the plastic surgeon. Br J Plast Surg 2004; 57: 348-53. [CrossRef]

11. Andereya S, Stanzel S, Maus U, Mueller-Rath R, Mumme T, Siebert $\mathrm{CH}$, et al. Assessment of leech therapy for knee osteoarthritis: a randomized study. Acta Orthop 2008; 79: 235-43. [CrossRef]

12. Goessl C, Steffen-Wilke K, Miller K. Leech therapy for massive scrotal hematoma following percutaneous transluminal angioplasty. J Urol 1997; 158: 545. [CrossRef]

13. Sağlam, N. 2011. Bazı tıbbi sülüklerin (Hirudo medicinalis L., 1758 ve Hirudo verbana Carena, 1820) ihracatı, korunması ve sürdürülebilirliği. Journal of Fisheries Sciences 2011; 5: 1-15.

14. KKGM Tıbbi sülük (Hirudo medicinalis ve Hirudo verbana) kota dağıımı komisyon raporu. Tarım ve Köyişleri Bakanlığı, Koruma Kontrol Genel Müdürlüğü. Ankara: 2011.s.2.

15. Gönenç B. Sülüklerin genel özellikleri, patojenite ve tedavi şekilleri. Kafkas Üniv Vet Fak Derg 2000; 6: 137-44.

16. Frodel JL Jr, Barth P, Wagner J. Salvage of partial facial soft tissue avulsions with medicinal leeches. Otolaryngol Head Neck Surg 2004; 131: 934-9. [CrossRef]

17. Mumcuoglu K Y, Pidhorz C, Cohen R, Ofek A, Lipton HA. The use of the medicinal leech, Hirudo medicinalisThe Internet Journal of Plastic Surgery 2007, in the reconstructive plastic surgery.

18. Kubo T, Yano K, Hosokawa K. Management of flaps with compromised venous outflow in head and neck microsurgical reconstruction. Microsurgery 2002; 22: 391- 5. [CrossRef]

19. Ulkür E, Yüksel F, Açikel C, Celiköz B. Effect of hyperbaric oxygen on pedicle flaps with compromised circulation. Microsurgery 2002; 22: 16-20. [CrossRef] 